\title{
Signo e sentido interno na filosofia da matemática pré-crítica
}

\author{
Ernesto M aria Giusti \\ Universidade São J udas Tadeu
}

\begin{abstract}
resumo Este artigo defende que, na Investigação sobre os princípios da teologia natural e da Moral, o conceito de "sentido interno" é central à reflexão kantiana sobre a matemática. Ele não deve ser entendido em sua acepção crítica, mas corresponde antes àquela derivada de Locke, pelo intermédio de Crusius, e se resume a uma reflexão mental sobre figuras e conceitos matemáticos. Ao incluir no sentido interno a dimensão simbólica do conhecimento matemático, Kant podia ainda ignorar um dos problemas centrais de sua reflexão madura sobre a matemática, a saber, como a inspeção de objetos matemáticos particulares permite formular provas e leis de caráter universal. I sto acentua diferenças, muitas vezes ignoradas, entre a filosofia da matemática crítica e pré-crítica.
\end{abstract}

palavras-chave Kant - Filosofia da Matemática - Sentido interno - Período pré-crítico

\section{Introdução}

Gostaria de propor aqui algumas observações a respeito do Preisschrift kantiano, a Investigação sobre os principios da teologia natural e da moral. Pretendo mostrar que este texto deve ser avaliado pelos seus méritos próprios: seria equivocado supervalorizá-lo por antecipar teorias críticas, assim como seria equivocado deixá-lo de lado por ter se tornado de algum modo "obsoleto" a partir da C rítica. Embora seja errado dizer que ele constitua o primeiro texto sobre 0 método de $K$ ant, é o primeiro dedicado explicita e exclusivamente ao tema e, talvez por representar 0 resultado de um longo período de reflexão, representa uma mudança

R ecebido em janeiro de 2005. A ceito em junho de 2005.

doispontos, Curitiba, São C arlos, vol. 2, n. 2, p.61-75, outubro, 2005 
drástica em relação aos seus primeiros textos. $\mathrm{N}$ ele, Kant assume 0 newtonianismo como modelo metodológico, alterando sua orientação inicial, tal como manifesta no escrito sobre as $\mathrm{F}$ orças $\mathrm{V}$ ivas. $\mathrm{N}$ aquele texto Kant está convencido de que não existe colaboração possível entre matemática e filosofia, pois cada uma aborda objetos distintos por meio de métodos incompatíveis. O s conceitos matemáticos são basicamente conceitos imaginários e quando houver uma contradição entre uma afirmação matemática e a realidade a solução é simples: deve-se rejeitar a matemática como enganosa, por ser mera quimera do espírito. $\mathrm{N}$ o longo silêncio de oito anos que se seguiu a essa obra, $K$ ant converte-se ao new tonianismo, como testemunha a $\mathrm{H}$ istória geral da naturez a e teoria natural do céu. Esta confrontação com o estrondoso sucesso da explicação matemática dos fenômenos naturais fornecida por $\mathrm{N}$ ewton torna impossível sustentar a tese da separação absoluta entre o real e a matemática. Do ponto de vista metafísico, isso significa recolocar a questão dos vínculos entre o lógico e o ontológico: $K$ ant, como a maior parte dos filósofos alemães fariam, interpreta esse problema como um problema sobre os princípios que regem o conhecimento, e em especial um problema sobre a relação do princípio de razão suficiente com o mundo físico, que este princípio parece condenar a um determinismo sem escapatória. Q uando aplicado ao terreno conceitual, do qual a matemática é o melhor exemplo, o princípio de razão suficiente equivale ao de nãocontradição, e embora possa garantir a certeza de um conhecimento, não pode garantir sua existência.

Para tanto é necessário deixar esse terreno puramente conceitual e examinar o real em busca de objetos que correspondam aos conceitos. O s juízos não-contraditórios, por si só, são incapazes de garantir a existência dos objetos pensados nesses juízos. A distinção entre ratio quid e ratio aur que daí emerge anuncia a separação entre certeza e verdade, se reflete no conjunto de textos de 1762-64 e parece reduzir a pergunta sobre a matemática a uma pergunta sobre a certeza que nela é possível atingir, e não a uma pergunta sobre seus fundamentos e a natureza de seus objetos. Essa redução é facilitada pela influência decisiva da crítica que $C$ rusius faz da ontologia wolffiana, e que corrobora a irredutibilidade da existência real à sua contraparte conceitual. Kant portanto começa a escrever 0 P reisschrift convencido, por um lado, de que a matemática está limitada 
pela lógica e, por outro, que ela é prova suficiente de que os conceitos que ela cria existem, já que a possibilidade lógica é a única exigência a ser preenchida pelos objetos da matemática . Em termos grosseiros, a situação pode ser descrita do seguinte modo: a evidência da matemática, entendida na linhagem de T schirnhaus, não permite afirmar que ela é falsa ou que suas leis não tenham qualquer relação com a realidade. $K$ ant ainda se move na mesma linha limítrofe entre o lógico e o psicológico que caracterizava Locke, o que lhe permite acreditar que uma análise dos elementos da matemática será suficiente para definir qual a natureza da sua certeza. Para levar a cabo essa empresa, os instrumentos privilegiados de que K ant se utiliza são o sentido interno e uma teoria da definição que atribui às definições matemáticas o caráter de definições reais, tornandoas capazes de criar seus próprio objetos e ao mesmo tempo dar-lhes a existência. É o sentido interno que permite tornar as representações objeto da reflexão do sujeito, e a experiência mental, realizada através dessa faculdade, será a garantia da existência dos objetos matemáticos sobre os quais se reflete. 0 apelo às definições reais tem ainda a função de estabelecer as regras que devem ser seguidas na criação dos objetos matemáticos, regras que não estão limitadas por nenhum fator, a não ser as leis da lógica. Todas as relações entre objetos matemáticos que for possível determinar através da não-contraditoriedade possuirão ipso facto uma realidade objetiva, que é contudo distinta da realidade objetiva dos objetos físicos. A diferença entre as definições da matemática e aquelas da filosofia é que estas últimas devem ser corroboradas pela experiência para serem declaradas válidas, enquanto a comparação das diferentes idéias e relações entre idéias em um juízo é uma garantia suficiente ao mesmo tempo da certeza do conhecimento, por seu caráter claro e distinto, e portanto evidente, e de sua realidade objetiva, sem nenhum apelo a algo que preencha o papel que mais tarde caberá à intuição. K ant não percebeu ainda, em 1764, que a independência da matemática em relação ao sensível simplesmente elimina o problema da relação entre a matemática e 0 real, mas não o resolve.

Formulei em outro local uma tentativa de interpretação do papel das definições no Preisschrift, por isso pretendo aqui me concentrar no papel do sentido interno e no confronto entre matemática e sensibilidade tal como estabelecido por Kant neste momento de sua evolução filosófica. 


\section{4}

A pós essa breve análise, buscarei expor as implicações desta leitura para as duas interpretações recentes mais influentes a respeito da teoria kantiana matemática, aquelas de Jaako H intikka (1982) e C harles Parsons (1992), no que diz respeito ao que estes autores afirmam sobre o período précrítico de Kant.

\section{Os objetos da matemática e o papel dos signos}

No parágrafo conclusivo de seu escrito sobre a $F$ alsa sutileza das quatro figuras silogísticas, $0 \S 6, K$ ant esboça uma teoria do juízo que fornece 0 pano de fundo para as reflexões do Preisschrift. 0 silogismo, diz Kant, é composto de juízos, e a inferência presente no interior do silogismo é ela mesma um juízo, não imediato, mas mediato. O ra, o que compõe os juízos, como seus elementos, são conceitos. $K$ ant conclui então que 0 juízo torna possível o conceito distinto de algo (deutlicher B egriff), enquanto só é possível chegar a um conceito adequado (vollständiger B egriff) através de um cadeia de inferências, de um raciocínio. Se representarmos corretamente as características (M erkmale) de um objeto, temos um conceito distinto deste objeto sem recorrer à inferência. 0 juízo não é 0 conceito distinto ele próprio, mas antes 0 ato mental que torna efetivamente distinto aquilo que potencialmente é claro e distinto. 0 ra, $\mathrm{K}$ ant, neste período, ainda defende uma teoria das faculdades cognoscitivas na qual o intelecto é a fonte única de toda verdade, e a faculdade de conhecimento nada mais é do que a faculdade do juízo. E é através do juízo que se efetua a passagem do "claro" ao "distinto", típica da reflexão wolffiana, fundamental para conceber a matemática e sua certeza. $M$ as qual é 0 fundamento do próprio juízo? K ant responde de modo hesitante:

"A minha opinião atual me leva a dizer que esse poder ou faculdade [que torna possível o juízo] não é outro senão o sentido interno <innerer Sinn>, isto é a faculdade de tornar as nossas próprias representações objeto de nosso pensamento." (KAN T, 1902, Ak. II, 60).

0 conceito de sentido interno permite resolver várias dúvidas a respeito do Preisschrift. Em primeiro lugar, ele significa o recurso à "experiência" na determinação das proposições matemáticas. Este apelo, no entanto, tal 
como aparece, por exemplo, na primeira sentença do $\S 2$ significa um recurso não ao objeto matemático desenhado, a uma figura ou ao contar nos dedos, mas sim, justamente, ao sentido interno. $N$ ele as representações que os conceitos matemáticos provocam em mim são consideradas e tornadas objeto do entendimento. A o manipular essas representações de acordo com regras os objetos matemáticos são criados, sem requererem confirmação externa. É errada portanto a tese segundo a qual se verificam as propriedades de todas as figuras geométricas de um determinado tipo, por exemplo os círculos, em um círculo concreto. A o contrário, é porque é possível ao sujeito conceber as propriedades do círculo como universais, pela ação do sentido interno que capta a clareza e a distinção dessas propriedades em um juízo, que um círculo concreto é uma prova da universalidade das conclusões do sujeito sobre os círculos em geral.

Para que isto se torne mais claro, é necessário examinar mais detidamente 0 que $K$ ant entende por sentido interno e qual significado devese atribuir-Ihe com respeito à matemática. A influência de Locke em Kant nesse ponto é evidente, e aquilo que é chamado de experiência interna em 1762, na Falsa Sutileza, corresponde aproximadamente ao sentido interno lockeano. A sua função é clara: ele pretende fornecer ao entendimento o material que a simples análise não pode lhe fornecer. $\mathrm{N}$ abert afirma que "ele é o resultado de um entendimento que se recusa a ser puramente intelectual" (N ABER T-1924, p. 218). Já foi mostrado antes que 0 desafio de $K$ ant no período examinado é dar conta de inferências que não são redutíveis à pura análise, ou à pura manipulação lógica de conceitos, e que necessitam de elementos extra-mentais para sua justificação: é o caso da existência e da causalidade. Esta é a razão de K ant negar à existência, no B eweisgrund, o status de predicado, e defini- lo como posição absoluta de uma coisa: qualquer que seja o significado que se atribui a esse termo, ele evidentemente representa a passagem do conceitual ao real, e faz parte da solução do problema, apresentado antes, das relações entre o lógico e o real, que ressurgem com toda sua força no caso da matemática, mas não apenas nele. U sando assim o conceito de sentido interno como um coringa no sistema filosófico que vai esboçando, K ant não hesita em mudar este conceito conforme a necessidade e a orientação de suas pesquisas. A ssim, no artigo de 1768 sobre A diferença das regiões do espaço, o sentido interno abarcará aquilo que logo depois será 
classificado como intuições puras, isto é o espaço e o tempo. Este conceito interessa $\mathrm{K}$ ant em todo seu percurso em direção a $\mathrm{C}$ rítica, mas 0 sentido interno (ou experiência interna) do Preisschrift guarda pouco em comum com seu homônimo crítico. Examinando a evolução de Kant, percebe-se que a sensibilidade só é reconhecida como uma fonte autônoma de conhecimento, distinta do entendimento, na $D$ issertatio de 1770. E apenas em 1772, na sua célebre carta a M arcus H erz, Kant se dá conta do problema das relações do objeto, enquanto algo fora do sujeito, com a representação, enquanto material dos juízos. A pergunta que leva $K$ ant ao criticismo é justamente "Sobre que fundamento repousa a relação daquilo que chamamos em nós representação com seu objeto" ou seja, como explicar a concordância entre representações e os objetos, na produção de conhecimento objetivo. No Preisschrift, não tendo ainda separado 0 entendimento da sensibilidade, a idéia de construção, trave de sustentação da filosofia crítica da matemática, mais que desnecessária, é impossível. $N$ este sentido deve-se tomar a afirmação de K ant no Preisschrift de que "a tarefa da matemática consiste em reunir conceitos dados de grandezas, que são claros e certos, e compará-los para ver quais resultados daí se pode obter" (KANT-1902, Ak. II, 278, grifo nosso). Isso significa que 0 entendimento toma como objetos o produto do sentido interno (e portanto as grandezas são dadas pelo sentido interno, e não pela sensibilidade tout court) e os compara através de juízos, como se depreende do $\S 6$ da F alsa Sutileza. A confusão entre sentido interno e sensibilidade é contudo explicável, já que até K ant os termos analítico e a priori, por um lado, e sintético e a posteriori, por outro, são sinônimos, e por isso, ao defender em 1764 que a matemática é sintética, e mesmo assim a priori, já que independente dos sentidos, K ant irá enredar-se inevitavelmente em dificuldades, pois ele próprio não havia percebido ainda com clareza esta limitação de sua teoria. A dificuldade que surge parece insolúvel no texto kantiano. Ainda que a síntese crie os objetos matemáticos e suas propriedades, só é possível conhecer essas propriedades e essa existência através de juízos, e o único requisito que os juízos devem sempre obedecer é a não contradição, o que significa em última instância que todos os juízos da matemática são analíticos: as referências ao procedimento sintético da matemática dizem respeito ao seu procedimento, mas não à natureza de suas proposições. A final, Kant afirma que "em matemática 
não tenho absolutamente nenhum conceito do objeto antes de a definição o dar" (KAN T-1902, A k. II, p. 283), portanto a única limitação que se impõe ao desenvolvimento de proposições sobre objetos matemáticos é a sua possibilidade lógica, isto é sua não contradição interna, o que fica claro em AK. II, 295-296: "a metafísica não possui pois princípios formais ou materiais da certeza que sejam de natureza diferente dos da geometria. $\mathrm{N}$ as duas ciências, a forma dos juízos tem lugar a partir dos princípios de identidade e contradição". A aporia em que K ant se enreda é portanto a seguinte: as proposições da matemática são funda mentalmente proposições analíticas com um conteúdo sintético. Kant não tem resposta adequada para isso, ou não percebe o problema. $\mathrm{N}$ ão é possível pois sustentar que a teoria crítica da matemática se limita a retomar as sugestões do Preisschrift, pois nele muito pouco é dito sobre a natureza da matemática e o que é dito é insatisfatório.

\section{Signos e certeza}

Parece ter sido a menção ao papel dos signos em matemática o que levou às interpretações errôneas de Parsons e $\mathrm{H}$ intikka segundo as quais a matemática já em 1764 depende diretamente do sensível. 0 primeiro ponto a ser levado em conta é que a menção aos signos aparece primeira mente em referência à aritmética, embora fosse mais natural (e assim a interpretaram $\mathrm{H}$ intikka e Parsons) associá-los explicitamente com a geometria. No Preisschrift, Kant afirma:

“Em ambos os tipos de aritmética [A ritmética e álgebra] o que é posto em primeiro não são as coisas mesmas mas os símbolos delas, junto com a designação especial do aumento ou diminuição, suas relações, etc.. D aí em diante, manipula-se esses signos de acordo com regras fáceis e certas, através da substituição, da combinação, subtração e vários outros tipos de transformações, de modo que as coisas significadas são completamente esquecidas no processo, até que finalmente, quando se chega a uma conclusão, o significado da conclusão simbólica é decifrado. Em segundo lugar, eu chamaria a atenção para o fato de que em geometria, para, por exemplo, descobrir as propriedades de todos os círculos, um círculo é desenhado; e neste círculo, ao invés de desenhar 
todas as possiveis linhas que nele se interceptam, desenho apenas duas. As relações que se estabelecem entre estas duas linhas são provadas; e a regra universal, que governa as relações entre as linhas intersecantes em todos os círculos são aqui consideradas in concreto" (KAN T-1902, A k. II, p. 278).

0 papel dos signos não é portanto genético, mas se limita a reforçar a certeza da matemática, reforçando sua clareza e distinção, e não por referir-se ao sensível, mas sim por constituir um procedimento puramente intelectual. $N$ ote- se por exemplo que os signos são os números (ou variáveis) e as figuras geométricas, mas não são os sinais das operações matemáticas; e no caso da geometria, embora os signos sejam as figuras, devo possuir além disso regras para possibilitar provas relativas a essa figura, que não podem ser extraídas do desenho apenas. Em ambos os casos, os signos são os depositários da certeza dos conceitos claros e distintos da matemática, mas não são eles próprios a fonte dessa certeza, já que o que importa não são os símbolos em si, mas as relações que se estabelecem entre eles. D esse modo, o papel dos símbolos no P reisschrift em nada coincide com a construção simbólica da $C$ rítica. A certeza do conhecimento matemático ainda depende fundamentalmente da evidência em sentido tschirnhausiano, e por isso o sentido interno deve se encarregar de mais uma função, qual seja a de permitir separar conceitos claros e distintos daqueles que não o são. Q uando Kant afirma em Ak., II, 296 que "a matemática (...) é mais fácil e tem uma participação maior na intuição", esta intuição é produto do sentido interno, e é clara e distinta, pois é produto da criação do objeto matemático através da definição:

"Possuímos a certeza na medida em que reconhecemos que é impossível que um conhecimento seja falso. 0 grau dessa certeza, quando considerado objective, depende da suficiência das notas da necessidade de uma verdade, por outro lado, quando considerado subjective, é tanto maior quanto mais intuitividade houver no conhecimento dessa necessidade" (KAN T-1902, A k. II, p. 290-91).

C omo K ant não distinguiu ainda entre sensibilidade e entendimento, essa intuição não pode ser uma intuição sensível, já que a sensibilidade não é ainda uma fonte autônoma de conhecimento. A intuição é exclusiva do 
entendimento, e mais especificamente de uma parte especial desta faculdade, o sentido interno. Só quando K ant houver concluído sua revolução copernicana esta teoria poderá ser satisfatória, pois então as intuições que fornecem o material da matemática serão dadas pelas intuições puras do espaço e do tempo. Se o exposto estiver correto, tanto $\mathrm{H}$ intikka quanto Parsons estão equivocados ao interpretar a teoria da matemática do Preisschrift como essencialmente a mesma da C rítica, especialmente no que se refere à relação entre matemática e sensibilidade. Ainda que as teses do Preisschrift conduzam a $C$ rítica, elas não são de modo algum as mesmas da C rítica. É o que sustenta a última parte deste trabalho.

\section{Conclusão}

$\mathrm{H}$ intikka e Parsons insistem na continuidade entre as teses pré-críticas e aquelas da crítica, e agora pode-se proceder a uma comparação mais exata entre elas. Sabe-se que a crítica standard da filosofia da matemática tal como ela se encontra por exemplo em R ussell ou C outurat, acerta em considerar que a matemática, em K ant, não é estritamente lógica. C ontudo, esta afirmação deve ser matizada para que faça sentido. É indiscutível que a matemática, nem em 1764, nem em 1781 ou depois, pode ser explicada através da lógica, já que K ant entende por lógica basicamente a teoria do silogismo. Isto não significa contudo ipso facto que qualquer reconstrução da filosofia da matemática através da lógica, entendida agora como lógica clássica de predicados (ou outros sistemas alternativos) seja sempre incompatível, ou seja incapaz de reproduzir a estrutura lógica da prova matemática em Kant (cf. FR IED M AN - 1985 e 1992, C ap. 1). I sto só poderia ser verificado de modo taxativo determinando exatamente qual o caráter da intuição que irá servir de base para a matemática no período crítico, e levaria a um exame da relação entre lógica transcendental e lógica formal que fosse capaz de determinar se, por exemplo, as estruturas fornecidas pelas intuições puras do espaço e do tempo são estruturas lógicas ou não, já que espaço e tempo são condicionantes da própria estrutura cognoscitiva. $N$ ão existe contudo uma resposta definitiva a essa pergunta (embora existam várias tentativas de resposta, uma delas do próprio $\mathrm{H}$ intikka) e, por isso, deve-se conceder a K ant o benefí- 
cio da dúvida, abstendo-se de formular conclusões sobre a redutibilidade da matemática à lógica em Kant, até porque, como visto, a matemática constitui uma espécie particular compreendida na ciência mais ampla que é a lógica.

N ão resta dúvida, entretanto, que tanto em 1764 quanto em 1781, a silogística e o princípio que a governa, a não-contradição, são incapazes de dar conta dos elementos materiais da matemática, que são fornecidos por elementos extralógicos, a intuição na C rítica e a definição real genética, controlada pelo seu caráter de clareza e distinção, no Preisschrift.

\section{R eavaliando Hintikka}

A interpretação de $\mathrm{H}$ intikka tem 0 objetivo explícito de responder a esse tipo de leitura de Kant. Para tanto, foi necessário que $\mathrm{H}$ intikka reformulasse o conceito de intuição para liberá-lo de seu caráter de "imagem mental", interpretando-o como equivalente à introdução de particulares nas provas matemática, particulares estes que tem a característica de representarem não apenas a si próprios enquanto particulares, mas toda a classe de objetos do mesmo tipo, universalizando a prova particular para a totalidade dos casos da mesma espécie de objetos. Sem entrar na discussão de como se dá essa universalização, cuja resposta nunca é encontrada de maneira clara em Hintikka, fica difícil não concluir que a intuição "dessensibilizada" proposta por H intikka é uma contribuição de Hintikka mais que do próprio Kant, já que, quer a imediatidade seja ou não acrescentada às notas características da intuição, esta depende sempre da sensibilidade, que apenas ela é capaz de fornecer intuições (e apenas em relação à sensibilidade a intuição pura adquire sentido). Se no K ant crítico esta concessão já é difícil de ser feita, isto vale ainda mais no caso dos textos pré- críticos: $\mathrm{H}$ intikka se equivoca ao tentar provar que a intuição não é sensível recorrendo ao Preisschrift, já que nele inexiste o conceito de intuição, ou melhor, ele se encontra ainda dissolvido em uma série de outros conceitos, tais como o de sentido interno, 0 de princípios materiais da ciência matemática, entre outros; além disso, a sensibilidade ainda não é uma fonte de conhecimento autônoma em 1764, e qualquer apelo à sensibilidade na fundamentação da matemática é muito mais descabido em 1764 do que o será em 1781. A prova que H intikka oferece para o caráter "não-sensível" da intuição baseia-se na 
admissão, por K ant, da possibilidade de uma intuição intelectual, que não é sensível e que portanto deve ser interpretada como uma estrutura puramente lógica. $\mathrm{O}$ ra, $\mathrm{K}$ ant apenas admite a possibilidade de uma intuição intelectual quando se trata de caracterizar o que a intuição humana não é, e portanto provar o caráter não-sensível recorrendo à intuição intelectual é deturpar $K$ ant.

Em defesa de $\mathrm{H}$ intikka, deve-se lembrar que ele reconhece que 0 conceito de intuição não existe no Preisschrift, mas ele usa isto justamente para concluir que "o método matemático estaria baseado na utilização de conceitos gerais in concreto, isto é, na forma de enunciados individuais" e que isto é o ponto de partida de todas as concepções posteriores da matemática em K ant. M ais uma vez essa afirmação deve ser rejeitada, pois ela não toca no ponto principal da teoria kantiana no Preisschrift: 0 que é importante não é que se trabal ha com enunciados individuais, mas que estes enunciados individuais constituem definições reais de um modo que é impossível aos enunciados, sejam particulares ou gerais, da metafísica, fazer. D ito de outro modo, ao insistir que o que caracteriza a teoria kantiana é o recurso aos individuais na prova de conceitos gerais, $\mathrm{H}$ intikka não chega a formular a pergunta crucial que é: como, destes conceitos individuais, chega- se à certeza e à universalidade características da matemática? A universalidade é conseguida pois as definições matemáticas criam seus objetos, que, por sua vez, contêm necessariamente a clareza e a distinção próprias dos objetos matemáticos, que tornam estes conhecimentos certos.

A mesma linha argumentativa pode ser utilizada para refutar a extensão da análise de Hintikka do conceito de intuição aos conceitos correlatos de construção e sinteticidade, que igualmente inexistem no P reisschrift. M esmo que existissem, eles não teriam as características que $\mathrm{H}$ intikka tenta lhes atribuir por analogia com a sua tentativa de reconstrução do conceito de intuição.

\section{R eavaliando Parsons}

Parsons elabora sua teoria na direção oposta de $\mathrm{H}$ intikka: enquanto este trata de "dessensibilizar" as intuições que fundamentam a matemática, Parsons procura saber em que sentido se deve interpretar a dependência que a matemática tem em relação à intuição sensível. D esde já pode- 
se dirigir a Parsons a mesma ressalva que era válida para H intikka, isto é, que a noção de intuição inexiste no Preisschrift, e que toda extensão dos conceitos pré-críticos em direção aos conceitos críticos deve ser feita cum grano salis, para dizer o mínimo. Parsons procura evitar essa objeção, equiparando o conceito de intuição a uma espécie da representação, mas em seguida define como essencial à intuição ou à representação o fato de ela ser o produto da afecção da mente por objetos. Parsons reduz assim todas as intuições a intuições sensíveis, mas apenas em um sentido figura do pode-se dizer que o sujeito é "afetado" pelas intuições puras do espaço e tempo, já que elas próprias irão constituir a sensi bilidade, e portanto são dela condição. Confrontado com a necessidade de reconhecer isto, Parsons reformula sua tese dizendo que de fato "a intuição que joga um papel na matemática não é o resultado direto da afecção de nossa mente pelos objetos" mas sim expressa uma percepção intuitiva das formas de intuição, e nesse sentido é uma intuição da sensibilidade. Ela também é sensivel pois depende do sentido interno.

$\mathrm{N}$ a linguagem de 1764, estas teses deixam claro a sua incompatibilidade com o que K ant realmente afirma no P reisschrift. Se se tentasse dizer que as representações são fruto da própria sensibilidade do sujeito, isto seria incompatível com a posição nitidamente cartesiana que $K$ ant ainda desposa em 1764, segundo a qual os sentidos não podem fornecer certeza, sendo esta uma exclusividade do entendimento, que consegue apreender a clareza e a distinção dos conceitos com os quais ele trabalha. Seria incompatível igualmente com o fato, ao qual acaba de fazer-se referência ao tratar de $\mathrm{H}$ intikka, de que $\mathrm{K}$ ant ainda não reconhece a sensibilidade como fonte de conhecimento. $M$ ais fecunda é a sugestão de que a intuição que atua na matemática depende do sentido interno. Embora, como visto, Kant ainda não compreenda o sentido interno do mesmo modo que o compreenderá na $C$ rítica, se se disser que 0 sentido interno produz no sujeito representações, isto provavelmente está correto também para o Preisschrift. A semelhança, contudo, não parece ir muito além disso. $\mathrm{Na}$ Crítica o sentido interno corresponde à intuição do tempo, e irá justificar dois conceitos fundamentais na matemática, aqueles de unidade (a unidade da duração em última instância permite derivar o conceito de número) e de sucessão, que coloca as condições de possibilidade das séries numéricas e das operações aritméticas básicas. 0 senti- 
do interno não é um mero auxiliar na construção dos conceitos matemáticos, mas a própria origem de al guns dos conceitos fundamentais desta ciência. No Preisschrift, no entanto, o papel reservado ao sentido interno é muito mais modesto, já que ele, enquanto reflexão sobre 0 conteúdo das representações (refletindo Locke) e enquanto fonte de certeza que permitir reconhecer a clareza e distinção dos conceitos (refletindo D escartes) é um valioso auxiliar na matemática, mas de modo al gum Ihe fornece seus conceitos básicos, como é o caso na $\mathrm{C}$ rítica.

0 utro aspecto da teoria crítica que não pode ser encontrado no Preisschrift diz respeito a distinção entre conceitos e representações. Parsons diferencia a intuição, que é singular e se refere imediatamente ao seu objeto, enquanto os conceitos são gerais e se referem mediatamente aos seus objetos. Em 1764, pela falta de uma correlação direta entre matemática e sensibilidade, a matemática ainda é uma ciência que, embora não sendo apenas conceitual, tem como objetos essencialmente conceitos, e a questão não é saber como as intuições preenchem os conceitos, mas sim como os conceitos da matemática podem ser ao mesmo tempo criados pelo espírito e certos ao serem aplicados ao mundo. A confusão que $\mathrm{K}$ ant ainda carrega entre conceitos e representações não permite levar Parsons ao pé da letra, pois então deveria ser dito que a matemática não pode possuir conceitos, já que Kant considera que as representações mediatas (como os conceitos segundo Parsons) são sempre obscuras, pelo menos de início, o que contraria a natureza dos conceitos matemáticos, que são evidentes, e portanto claros e distintos. 0 utro modo de refutar esta tese é relembrar a teoria do juízo que encontramos na Falsa Sutileza, que afirma que 0 ato de inferência constitui sempre um juízo mediato. O ra, é possível obter conceitos matemáticos a partir de outros conceitos, por exemplo o conceito de diagonal a partir do conceito de quadrado, o que significa que a matemática trabalha não apenas a partir de conceitos, mas a partir de conceitos mediatos igualmente. Q ue a matemática seja uma ciência que faz basicamente afirmações de existência (de seus objetos) apenas corrobora este fato, pois sua particularidade é justamente permitir chegar a afirmações de existência pelo caminho dos conceitos. 0 papel da construção simbólica, para Parsons, é justamente "preencher" os conceitos matemáticos, fornecendo-Ihes uma intuição correspondente, 
mas o Preisschrift apresenta uma teoria diferente, segundo a qual a correção dos conceitos matemáticos, verificada pela evidência dos conceitos matemáticos e dos símbolos que os representam é ela própria condição suficiente para afirmar a existência do objeto correspondente. $N$ ão existe nenhum tipo de limitação da matemática pelas representações sensíveis, como existe na $\mathrm{C}$ rítica da $\mathrm{R}$ azão Pura. C om efeito, a única limitação imposta em 1764 à matemática é a não-contradição de seus conceitos, entendida muito mais no sentido psicológico de "poder ser pensado", reminescente de Crusius, do que em um sentido estritamente lógico. Em 1764 a matemática ainda é uma ciência formal cujo critério de verdade é a evidência, entendida como clareza e distinção dos conceitos e de suas notas características, e cujos limites são impostos apenas pela incapacidade do entendimento em conceber certos conceitos, e não pela natureza da estrutura sensível, já que nada nos textos permite inferir uma relação de dependência ou condicionamento entre a sensibilidade e o conteúdo da matemática nesse estágio.

\section{Referências bibliográficas}

FR IED M AN , M . 1985. Kant'sT heory of Geometry", in: T he Philosophical R eview, 94.

$\mathrm{H}$ arvard U niversity Press.

. 1992. K ant and the exact sciences, C ambridge, M ass.,

HIN TIKKA, J. 1982. "Kant on the mathematical method" (1a. edição:

The M onist, 1967, vol. 51, pp. 352-375), in: R alph WALKER (org.), $\mathrm{K}$ ant on pure reason, $\mathrm{C}$ ambridge, $\mathrm{C}$ ambridge $\mathrm{U} \mathrm{P}$.

KAN T, I. 1902 em diante. K antsW erke, Ed. Königlich Preussischen A kademie der W issenschaften, Berlin, G eorg R eimer (A kademie TextAusgabe, Berlin, Walter de Gruyter \& C o.).

N ABERT, J. 1924. "L 'éxpérience interne chez kant" em R evue de métaphysique et de morale, n. 31. 
PAR SO N S, C. 1992. "Kant's philosophy of mathematics" (1a. edição 1969, in: S. M orgenbesser, P. Suppes e M . W hite eds., M athematics in philosophy: essays in honor of $E$ rnest $N$ agel. Saint $M$ artin's Press), in: $C$ arl Posy (ed.) K ant's philosophy of mathematics - M odern essays. D ordrecht, Kluwer.

doispontos, Curitiba, São Carlos, vol. 2, n. 2, p.61-75, outubro, 2005 


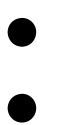

